\title{
A INTERFACE SUJEITO-AGÊNCIA NO CAMPO CURRICULAR: QUE CONTRIBUIÇÕES DAS PESQUISAS (AUTO)BIOGRÁFICAS?
}

CARMEN TERESA GABRIEL

Universidade Federal do Rio de Janeiro

\section{NATÁLIA RODRIGUES MENDES}

Universidade Federal do Rio de Janeiro

RESUMO Considerando a intensificação da inserção dos estudos narrativos e/ou (auto)biográficos no campo do currículo, nos últimos anos, o objetivo deste texto é refletir sobre a articulação sujeito-agência, nos estudos do campo curricular, a partir das contribuições teóricometodológicas das pesquisas (auto)biográficas. Nosso interesse em compreender os processos de subjetivação em contextos de formação, nos faz apostar nesta abordagem como um campo proficuo para pensar a complexa relação entre sujeito e estrutura, na leitura política do social. Trata-se de reconhecer a potencialidade analítica das narrativas (auto)biográficas, na compreensão da agência para além do par binário resistência e sujeição, hegemonicamente mobilizado nas análises do campo educacional, como polos dicotômicos e excludentes. Em diálogo com autores como Judith Butler (2014), Gert Biesta (2013) Christine Delory-Momberger (2011a; 2011b; 2012; 2014; 2016; 2017) e Saba Mahmood (2005; 2006), apostamos teoricamente no entendimento de que "tornar-se sujeito" ou produzir subjetividades políticas depende diretamente da regulação e, portanto, os meios que garantem a subordinação dos sujeitos são os mesmos que possibilitam a rebeldia ou o deslocamento em relação a essa sujeição.

Palavras-chave: Agência. Sujeito. Currículo. Estudos (auto)biográficos.

ABSTRACT THE SUBJECT-AGENCY INTERFACE IN THE CURRICULAR FIELD: WHAT CONTRIBUTIONS OF (AUTO)

\section{BIOGRAPHICAL RESEARCH?}

Considering the intensification of the insertion of narrative and / or (auto) biographical studies in the field of curriculum in the last years, this paper aims to reflect on the subject-agency articulation in the 
studies of the curricular field from the theoretical-methodological contributions of the (auto) biographical researches. Our interest in understanding the processes of subjectivation in contexts of formation leads us to invest on this approach as a profitable field to think about the complex relation between subject and structure in the political reading of social. It is about recognizing the analytical potentiality of (auto) biographical narratives in the understanding of the agency beyond the binary pair resistance and subjection, hegemonically mobilized in the analyzes of the educational field, as dichotomous and excluding poles. In a dialogue with authors like Judith Butler, Gert Biesta, Christine Delory-Momberger and Saba Mahmood, we theoretically invest in the understanding that 'becoming subject' or producing political subjectivities depends directly on regulation. Therefore the means that ensure subordination of the subjects are the same that provide the possibilities for rebellion or displacement in relation to this subjection.

Keywords: Agency. Subject. Curriculum. (Auto)biographical studies.

\section{LA INTERFAZ SUJETO-AGENCIA EN EL CAMPO}

\section{CURRICULAR: ¿CUÁLES SON LOS APORTES DE LAS INVESTIGACIONES (AUTO)BIOGRÁFICAS?}

Considerando la intensificación de la inserción de los estudios narrativos y/o (auto)biográficos en el campo curricular en los últimos años, el objetivo de este texto es reflexionar sobre la articulación sujeto-agencia, en los estudios de dicho campo, a partir de los aportes teórico-metodológicos de las investigaciones (auto)biográficas. Nuestro interés por entender los procesos de subjetivación en contextos de formación nos hace apostar a este abordaje como un campo proficuo para pensar en la compleja relación entre sujeto y estructura, en la lectura política de lo social. Se trata de reconocer la potencialidad analítica de las narrativas (auto)biográficas en el entendimiento de la agencia, más allá del par binario resistencia y sometimiento, hegemónicamente movilizado en los análisis del campo educativo, como polos dicotómicos y excluyentes. En diálogos con autores como Judith Butler, Gert Biesta, Christine Delory-Momberger y Saba Mahmood, apostamos teóricamente al entendimiento de que 'constituirse como sujeto' o producir subjetividades políticas depende directamente de la regulación y que, por lo tanto, los medios que garantizan la subordinación de los sujetos son los mismos que hacen posible la rebeldía o el desplazamiento en relación a ese sometimiento.

Palabras clave: Agencia. Sujeto. Currículum. Estudios (auto)biográficos. 
[...] reintroduzir a contingência contra a necessidade no centro das relações políticas é pois, reconhecer a flutuação do sentido atribuído pelos atores aos seus atos, ao seu contexto e às suas próprias trajetórias biográficas; é também estudar as incessantes tentativas para fixar sentidos, para estabilizar a significação das lutas políticas, desenhar as linhas de corte imutáveis no seio do social, restabelecendo assim os laços com a certeza, abrindo um acesso a uma realidade e uma verdade alegadamente livre das distorções ideológicas. (SOMMERER, 2005, p. 194, tradução livre) ${ }^{1}$

O objetivo deste texto ${ }^{2}$ é refletir sobre a interface "sujeito-agência", nos estudos do campo curricular, a partir das contribuições teórico-metodológicas das pesquisas (auto) biográficas. Nosso interesse em compreender os processos de subjetivação, em contextos de formação como a escola ou a universidade pública, nos faz apostar neste diálogo como um caminho proficuo para pensar a complexa relação entre sujeito e estrutura, na leitura política do social a partir de uma postura epistêmica pós-fundacional (MARCHART, 2009; LACLAU; MOUFFE, 2004).

Tal postura se inscreve em um horizonte teórico que se caracteriza pela emergência e consolidação da crítica radical a noções como "origem" e "fundamento último" - sobre as quais se sustentam as perspectivas essencialistas e/ou deterministas - bem como pela afirmação do lugar político instituinte da lin-

1 Réintroduire la contingence contre la nécessité au cœur des rapports politiques, c'est alors reconnaître le flottement du sens donné par les acteurs à leurs actes, à leur environnement et à leur propre cheminement biographique ; c'est aussi étudier leurs tentatives incessantes pour fixer ce sens, pour stabiliser la signification des luttes politiques, dessiner des lignes de partage immuables au sein du social, et renouer alors avec la certitude, ouvrir un accès à une réalité et à une vérité prétendument affranchies des distorsions idéologiques. (SOMMERER, 2005, p. 194)

2 A produção deste texto se inscreve nos estudos desenvolvidos no âmbito do projeto Currículo como espaço biográfico: conhecimento, sujeitos e demandas, sob a coordenação da professora Carmen Teresa Gabriel, e conta com o apoio da FAPERJ/CNE, Processo E-26 202.931/2017. guagem na produção tanto da ordem social quanto do conhecimento sobre a mesma em meio a processos de significação em permanente disputa. Definida "como uma constante interrogação de figuras metafísicas fundacionistas" (MARCHART, 2009, p. 14), ${ }^{3}$ esta abordagem discursiva não se confunde, no entanto, com um antifundacionismo. Ao contrário, como deixa entrever a citação de Sommerer (2005) trazida aqui como epígrafe, ela investe no paradoxo que se expressa pelo reconhecimento simultâneo da ausência de um fundamento último, sobre o qual se constrói o social, e da necessidade ou inevitabilidade da produção de fundamentos contingentes e provisórios. Em nossas pesquisas, temos, assim, procurado explorar as possibilidades abertas pela incorporação desse paradoxo, para pensar os processos de estruturação do campo curricular e, mais recentemente, a produção, posicionamento e ação dos sujeitos nesta estrutura contingencialmente produzida.

$\mathrm{Na}$ perspectiva que vimos trabalhando, o que está em jogo é o entendimento e o uso de categorias como "objeto" e "sujeito" no âmbito das ciências sociais e seus efeitos na produção do currículo. Inscrito nesse movimento teórico mais amplo, este texto investe na ideia de "currículo como espaço biográfico", compreendido como um espaço no qual se entrecruzam processos de objetivação e de subjetivação que configuram sua própria estruturação. Dito de outro modo, "um singular habitado pela pluralidade [...] um espaço entre que clausura a antinomia, revelando a imbricação profunda entre indivíduo e sociedade (ARFUCH, 2010, p. 340, grifos nossos) em meio a processos de estruturação discursiva de uma ordem social desigual.

Neste texto, interessa-nos, mais especificamente, explorar pistas teórico-metodológi-

3 No original: "una constante interrogación por las figuras metafísicas fundacionales". (MARCHART, 2009, p. 14) 
cas para as análises sobre as possibilidades de articulação entre as signifixações (LEITE, 2010) de "sujeito" e de "subjetividade política"|"agência" produzidas nas pesquisas do campo curricular. A compreensão da interface currículo-subjetivação, a partir de uma abordagem discursiva, tem sido foco de estudos curriculares que dialogam com as contribuições dos pós-estruturalismos, em suas diferentes inscrições (estudos feministas, estudos culturais, pós-fundacionismo, teorias queer, estudos subalternos). Nesses quadros de inteligibilidade, a mobilização de termos, como "norma", "normatividade", "performatividade", “subalternidade", “hegemonia", e "antagonismo", oferece ferramentas de análise potentes que operam e investem no deslocamento de discursos hegemonizados no campo acadêmico sobre a categoria "sujeito", em particular quando associada às ideias de "emancipação", "resistência", "subversão", descortinando, assim, outros caminhos para se pensar a questão da agência. Este texto foi construído justamente em torno da ideia, talvez um tanto óbvia, mas nem por isso ingênua ou desinteressada, que a potência heurística do significante "agência" como categoria de análise pressupõe um entendimento de "sujeito", isto é, pressupõe que os processos de significação desses dois significantes - "agência" e "sujeito" - se inscrevam em teorizações sociais que compartilhem uma mesma postura epistêmica.

Em nossos estudos curriculares inscritos na perspectiva pós-fundacional, temos nos interrogado ${ }^{4}$ sobre como continuar pensando politicamente o mundo da "escola", da "formação" ou mais especificamente a questão da "relação com o conhecimento" (GABRIEL, 2016;

4 Referimo-nos ao Grupo de Estudos Currículo, Conhecimento e Ensino de História (GECCEH), que se insere no Laboratório Núcleo de Estudos do Currículo (LaNEC) da Faculdade de Educação da UFRJ, sob a coordenação da professora Carmen Teresa Gabriel.
2017; 2018a, 2018b), a partir do campo educacional, quando deixamos de lado a crença no "sujeito do conhecimento", percebido como o sujeito portador de uma razão cartesiana racional que paira sobre determinismos sociais e/ou metafísicos, forjando sua consciência, sua vontade e garantindo sua autonomia. Do mesmo modo, questionamos: como operar com o deslocamento da ideia de um sujeito "em geral" para uma compreensão do sujeito enquanto um indivíduo singular (BIESTA, 2013, p. 66), sem reatualizar discursos individualistas e essencialistas? Ou ainda: como pensar o quem da educação depois da crítica radical de toda possibilidade de definição prévia do sujeito e da subjetividade humana?

Entre as pistas que vimos explorando para responder a essas questões, destacamos, neste texto, os aportes teóricos da pesquisa biográfica nas últimas duas décadas (DELORYMOMBERGER, 2010; 2011a, 2011b, 2014; 2016; 2017; NIEWIADOMSKY, 2012; SOUZA, 2007), em particular o que eles contribuem para a reflexão sobre o entendimento de "sujeito" e consequentemente, do significante "agência" na pauta pós-fundacional. Isso implica, como exploraremos ao longo do texto, pensar a interface sujeito-agência sem associá-la ao par binário resistência e sujeição, nos distanciando, assim, das análises deterministas e/ou essencialistas nas quais esses significantes tendem a ser percebidos como polos dicotômicos e excludentes. A interlocução com essa abordagem a partir do campo educacional não é aleatória, tampouco inovadora. Afinal, como nos aponta Newiadomsky:

[...] a pesquisa biográfica se interessa, há muitos anos, pela estreita relação entre formação, aprendizagem e biografia. Trata-se de compreender a maneira pela qual os atores significam suas experiências de formação e de aprendizagem bem como o papel que desempenham as instituições educativas e formativas na construção de biografias individuais e nos proces- 
sos de socialização. (NIEWIADOMSKI, 2012, p. 63, tradução livre) $)^{5}$

Para além desse interesse em termos de objeto de investigação, vimos apostando em nossos estudos curriculares que a pesquisa biográfica oferece possibilidades de entendimento da categoria "sujeito" e de "subjetividade política" que permitem, como procuraremos evidenciar mais adiante, sustentar uma leitura política da interface currículo-subjetivação-agência consistente do ponto de vista teórico-metodológico, no âmbito da perspectiva pós-fundacional aqui defendida

Organizamos este ensaio em duas seções. $\mathrm{Na}$ primeira, apresentamos uma leitura da pesquisa (auto)biográfica sublinhando a potencialidade analítica que a mesma oferece para repensar politicamente a categoria "sujeito". Na segunda seção apresentamos em linhas gerais o entendimento de "agência", em circulação no campo curricular, que consideramos potente para operar em nossos estudos. Para finalizar, tecemos algumas considerações teóricas destacando as articulações possíveis e disponíveis entre "sujeito biográfico" e "agência" com o intuito de reforçar a potência do diálogo teórico pretendido.

\section{Sujeito biográfico como chave de leitura política potente}

Podemos pensar que o termo 'sujeito' não convém para designar um elemento que é mais do lado da resistência do que da vontade, da efração do que da consciência, da alteridade do que da identidade própria. Mas podemos por isso nos passar do mesmo? Po-

5 La recherche biographique s'intéresse depuis de nombreuses années á la relation étroite ente formation, apprentissage et biographie. Il s'agit ici de comprendre la manière dont les acteurs font signifier leurs expériences de formation et d'apprentissage ainsi le rôle qui jouent les institutions éducatives et formatives dans les constructions biographiques individuelles et dans le processus de socialisation. (NIEWIADOMSKI, 2012, p. 63) demos também pensar que é o pior termo, à exceção de todos os outros. (GAUJELAC, 2009, p. 123 , tradução livre) ${ }^{6}$

Em artigo recente, Delory-Momberger (2017) interroga-se sobre a natureza do saber nomeado "pesquisa biográfica", sublinhando sua inscrição nos "ares de nosso tempo presente". Para essa autora, "uma das maneiras de compreender as questões aos quais a pesquisa biográfica em educação busca responder é questionar a relação entre o contexto societário no qual esta vertente de pesquisa se desenvolve, seu projeto e os objetos e formas de saber que ela se dá" (DELORY-MOMBERGER, 2017, p. 11, tradução livre).7 Trata-se assim, de explicitar as condições de produção de um saber, evidenciar sua episteme (FOUCAULT, 1966), isto é, a maneira de pensar e significar o mundo hegemonizada em um contexto histórico específico.

Nessa perspectiva, a compreensão do projeto epistemológico da pesquisa biográfica que emerge nas últimas décadas do século passado implica em inscrevê-lo no que pode ser nomeado de forma abrangente por "tempos pós". A despeito da compreensão deste prefixo - ou das variações discursivas mobilizadas para nomear o espaço-tempo presente -, importa reconhecer as reverberações que seu uso provoca na própria postura epistêmica que norteia as leituras políticas do social em nossa contemporaneidade. Referimo-nos mais especificamente, neste texto, aos efeitos

6 On peut penser que le terme de "sujet" convient mal pour désigner une composante qui est plus du coté de la résistance que de la volonté, de l'effraction propre que de la conscience, de l'altérité que de l'identité Mais peut-on pour autant s'en passer? On peut aussi penser que c'est le plus mauvais terme, à l'exception de tous les autres. (GAUJELAC, 2009, p. 123)

7 No original: "une des manières de cerner les questions auxquelles la recherche biographique en éducation cherche à répondre est d'interroger la relation entre le contexte sociétal dans lequel ce courant de recherche développe son projet et les objets et formes de savoir qu'il se donne". (DELORY-MOMBERGER, 2017, p. 11) 
do que ficou conhecido como "virada ontológica" sobre o entendimento de "sujeito" como categoria analítica.

Entendemos que em tempos de "crise do humanismo", da "morte do sujeito" e da crítica da "filosofia da consciência", abrem-se outras possibilidades de significação de sujeito que investem na potencialidade heurística de significantes como "biográfico" ou "biografização", de um outro lugar epistêmico. Não é por acaso que Delory-Momberger (2016) afirma que "a questão do projeto epistemológico da pesquisa biográfica consiste em reafirmar no coração desse projeto [...] a especificidade e a centralidade do fato biográfico" (DELORYMOMBERGER, 2016, p. 135-136, tradução livre e grifos nossos). ${ }^{8}$

Mas quais são os processos de subjetivação que a mobilização desta expressão tenciona nomear? Que discursos sobre processos de subjetivação, o uso do adjetivo "biográfico" na definição de "fato" permite reforçar e/ou deslocar?

A formulação dessas questões exige que nos detenhamos sobre o próprio sentido de biografia com a qual opera essa abordagem. 0 uso desse termo implica em trazer para a reflexão a dimensão da temporalidade como elemento importante da cadeia discursiva definidora de sujeito. Temporalidade essa que só se pode acessar por meio da narrativa. Inscrevemos nossas ações, os significados que thes atribuímos em histórias que constroem e organizam a nossa experiência em uma lógica narrativa. $O$ fato biográfico é produzido no e com o tempo, isto é, em meio às narrativas que nos produzem, nos permitem tornarmos sujeitos. Isso significa que, para a pesquisa biográfica, não existe um sujeito a priori cuja história es-

8 No original: "la question du projet épistémologique de la recherche biographique et c'est réaffirmer, au cœur de ce projet - pour le dire d'entrée de manière très synthétique -, la spécificité et la centralité du fait biographique". (DELORY-MOMBERGER, 2016, p. 135-136) taria à espera para ser narrada, mas sim histórias, narrativas possiveis de serem construídas, articuladas, permitindo acessar os múltiplos processos de subjetivação. 0 sujeito biográfico emerge, assim, da hegemonização de narrativas particulares que mobilizam processos de subjetivação, entendidos como processos inacabados, simultaneamente simbólicos, políticos e contingenciais.

Assim, como processo de formação que confere forma e sentido às experiências dos sujeitos, a narrativa (auto)biográfica institui-se como uma hermenêutica da experiência (DELORY-MOMBERGER, 2011a), outorgando aos sujeitos "o lugar de protagonistas de suas vidas, transformando acontecimentos, indivíduos e atitudes em episódios, intrigas e personagens" (DELORY-MOMBERGER, 2011a, p. 341). Neste sentido, a narrativa se apresenta não apenas como a forma por meio do qual os sujeitos expressam o sentimento de suas existências, mas o espaço em que o ser humano elabora e experimenta a sua história de vida. Assim, para Delory- Momberger, a biografia é:

[...] uma dimensão do agir humano que permite aos indivíduos, dentro das condições de suas inserções sócio-históricas, integrar, estruturar, interpretar as situações e os acontecimentos vividos. Tal atividade de biografização apresenta-se como uma hermenêutica prática, um marco de estruturação e de significação da experiência que permite ao indivíduo criar uma história e uma forma própria - uma identidade ou individualidade - para si mesmo. (DELORYMOMBERGER, 2011a, p. 342)

Entre os argumentos desenvolvidos nos debates internos ao campo da pesquisa biográfica, a questão da construção da experiência assume um lugar de destaque na compreensão dos processos de biografização, de subjetivação. Desse modo, entendemos que a análise do sentido atribuído à interface sujeito -experiência pode ser uma entrada produtiva no canteiro em plena efervescência da pesqui- 
sa biográfica, para explorar teoricamente as questões anteriormente formuladas.

A leitura da bibliografia especializada sobre pesquisa biográfica destas duas últimas décadas permite afirmar que essa abordagem atribui um sentido à interface sujeito-experiência que se distancia radicalmente daqueles que contribuem para que a noção da experiência seja reificada, ao mobilizá-la com o propósito de ocupar o lugar de fundamento último em substituição ao cogito-cartesiano. Ao reconhecer que falar da construção da experiência é falar da maneira como cada um de nós vivemos, experienciamos e conhecemos (DELORYMOMBERGER, 2016), esse enfoque permite entrever uma maneira de escrever ou falar de experiência, sem essencializá-la. Afinal, como os estudos feministas já vêm nos provocando a pensar, há mais de duas décadas:

Não são os indivíduos que têm experiência, mas os sujeitos é que são constituídos através da experiência. A experiência de acordo com essa definição, torna-se, não a origem de nossa explicação, não a evidência autorizada (porque vista ou sentida) que fundamenta o conhecimento, mas aquilo que buscamos explicar, aquilo sobre a qual se produz conhecimento. (SCOTT, 1999, p. 5)

Esse mesmo tipo de compreensão está presente em Larossa (2002), ao afirmar que "a experiência não é o que acontece, mas o que nos acontece" (LAROSSA, 2002, p. 27) abrindo pistas para se pensar, de um outro lugar epistêmico, as articulações entre o "sujeito da experiência", o "sujeito do conhecimento" e o "sujeito político".

Para além da forma como o termo experiência é significado nos estudos biográficos, sua mobilização permite reintroduzir o lugar do sujeito em seu duplo-sentido: "como sujeito-sujeitado e como sujeito-agente" (RETAMOZO, 2012, p. 343, tradução livre). ${ }^{9}$ Localiza-

9 No original: "como sujeto sujetado y como sujeto agente". (RETAMOZO, 2012, p. 343) da igualmente no campo da chamada virada hermenêutica, a pesquisa biográfica legitimase como método de investigação/formação em que os fenômenos sociais são entendidos "como textos e a interpretação como atribuição de sentidos e significados das experiências individuais e coletivas" (SOUZA, 2007, p. 65). Nas palavras de Souza:

Do ponto de vista metodológico, a abordagem biográfico-narrativa assume a complexidade e a dificuldade em atribuir primazia ao sujeito ou à cultura no processo de construção de sentido. Ao longo de seu percurso pessoal, consciente de suas idiossincrasias, o indivíduo constrói sua identidade pessoal mobilizando referentes que estão no coletivo. Mas, ao manipular esses referentes de forma pessoal e única, constrói subjetividades, também únicas. Nesse sentido, a abordagem biográfico-narrativa pode auxiliar na compreensão do singular/universal das histórias, memórias institucionais e formadoras dos sujeitos em seus contextos, pois revelam práticas individuais que estão inscritas na densidade da História. (SOUZA, 2007, p. 65)

Essa percepção é importante nas análises do campo das ciências sociais pois, como nos lembra Howarth (2000), "se o conceito de posição do sujeito explica as múltiplas formas pelas quais indivíduos são produzidos como atores sociais, o conceito de subjetividade política capta a maneira como atores sociais agem" (HOWARTH, 2000, p. 108, tradução livre).10

0 primeiro sentido remete ao posicionamento ou ao assujeitamento do indivíduo aos processos de estruturação mais amplos nos quais todo indivíduo se inscreve. Com efeito, o termo experiência carrega o potencial de exercer uma função discursiva articuladora entre o individual e o social, ao evocar simultaneamente a singularidade de uma trajetória e dar um sentido comum às práticas coletivas, sejam

10 No original: "if the concept of subject position accounts for the multiple forms by which individuals are 'produced' as social actors, the concept of political subjectivity captures the way in which social actors act". (HOWARTH, 2000, p. 108) 
elas familiares, profissionais, culturais, outras experiências associativas ou comunitárias, a despeito das diferentes formas que cada indivíduo possa com elas interagir. Com efeito, as narrativas biográficas produzidas pelos indivíduos posicionados como atores sociais, em diferentes contextos discursivos, colocam em evidência práticas hegemonicamente sedimentadas e provisoriamente estabilizadas em torno de significantes capazes de regular a dispersão em um sistema de diferenças.

Importa sublinhar, no entanto, que a potencialidade heurística de conceitos, como biografização ou narrativas de si, não consiste apenas em dar visibilidade aos processos de estruturação nos quais os indivíduos são posicionados como atores sociais. Eles oferecem principalmente pistas de investigação para pensarmos em que medida a interface sujeito -experiência contribui para subverter tanto a ordem desigual no qual ele se inscreve quanto as formulações teóricas que explicam a ação política do sujeito seja por um "voluntarismo absoluto", seja pela sua redução ao papel de reprodução das estruturas pré-construídas.

Afinal, como nos lembra Scott (1999), “o projeto de tornar a experiência visível", dependendo como este termo for significado, ao invés de permitir "um exame crítico do funcionamento do sistema e de sua historicidade, [...] reproduz seus termos" (SCOTT, 1999, p. 5). Para essa autora, "qualquer maneira que considere o significado como transparente reproduz, ao invés de contestar, sistemas ideológicos estabelecidos" (SCOTT, 1999, p. 4). Assim, "o que conta como experiência não é nem auto-evidente, nem definido, é sempre contestável, portanto sempre político" (SCOTT, 1999, p. 20).

Nessa perspectiva, temos explorado como o investimento teórico nos estudos biográficos - em particular no que eles ajudam a pensar o poder de agir singular - pode produzir efeitos desestabilizantes de uma ordem social desi- gual, e, no caso que nos interessa, da ordem discursiva curricular. A potencialidade heurística de expressões como "sujeito biográfico" ou um "ser social singular" (DELORY-MOMBERGER, 2012) pode ser explorada em sua ambivalência pelos usos possiveis de serem feitos por parte de diferentes projetos políticos e matrizes paradigmáticas disponiveis no cenário contemporâneo das ciências sociais. Afinal, as narrativas biográficas não poderiam ser entendidas, como ontologia do "tornar-se presença" do sujeito, de que nos fala Biesta (2013), mobilizadoras de coordenadas espaciais e temporais em contextos discursivos específicos?

\section{A categoria "agência" na abordagem pós-fundacional}

O homem não encontra sua liberdade 'fugindo' de sua condição, mas a aceitando para melhor enfrentá-la a fim de se construir a partir dela. O sujeito é antes de tudo assujeitado e é nesse próprio assujeitamento que ele encontra os elementos que vão the permitir de se construir como sujeito. 0 processo de subjetivação inscreve o indivíduo em uma investigação permanente de mediações face às contradições que o atravessam. (GAUJELAC, 2009, p. 195, tradução livre) $)^{11}$

Os deslocamentos conceituais em relação à categoria "sujeito" provocados pela emergência e consolidação, no campo das ciências sociais, de novas posturas epistêmicas, entre elas a pesquisa biográfica, têm produzido efeitos nos debates internos em torno da noção de "agência". Nossa intenção aqui não é a de produzir uma cartografia desse debate, mas, sim, a de apresentar algumas apropriações

11 “L'homme ne trouve pas sa liberté en échappant à sa condition, mais en l'acceptant pour mieux la dépasser a fin de se construire à partir d'elle. Le sujet est avant tout assujetti, et c'est dans cet assujettissement qu'il trouve les éléments qui vont lui permettre de se construire en sujet. Le processus de subjectivation inscrit l'individu dans une recherche permanente de médiations face aux contradictions qui le traversent". (GAUJELAC, 2009, p. 195) 
do mesmo na pauta pós-fundacional, disponível no campo curricular, que nos interessa continuar explorando em nossas pesquisas. Em linhas gerais, interessa-nos a aproximação dessa noção, pois entendemos que ela tem ocupado, no âmbito de diferentes áreas de conhecimento - sociologia, antropologia, ciência política, história -, a função discursiva de um ponto articulador/nodal em torno do qual giram as discussões que operam com a complexa relação entre estrutura e sujeito.

Como pensar a produção de "subjetividades políticas" de forma a operar na e com a aporia do singular e coletivo, do individual e social? Como abordar em nossas interpretações sobre as ações sociais a tensão entre o peso da estrutura e a capacidade de agir dos sujeitos posicionados como atores sociais em contextos específicos, quando não apostamos em um modelo de transformação de sentido unívoco no qual se opera com a ideia de "um mundo melhor", entendido muitas vezes como esvaziado de relações de poder hegemônicas? Quando entendemos, igualmente, que a nossa "condição biográfica", como afirma DeloryMomberger (2010), não é apenas uma possibilidade do sujeito singular "tonar-se presença", mas também uma condição do sujeito assujeitar-se às novas formas de regulação social em nossa contemporaneidade? Afinal, é a partir do reconhecimento dessa condição que podemos pensar as narrativas do eu e do nós como subversão e/ou controle de uma lógica cultural hegemônica. Esse tipo de reflexão é crucial para não perdermos de vista as injunções políticas de nosso presente e simultaneamente não confundir o retorno do "indivíduo", entendido como sujeito único e singular pela maneira como responde ao outro, com o retorno do individualismo normativo ou de uma celebração dos particularismos identitários. Trata-se, portanto, de pensar o político por um outro caminho, de um outro lugar epistêmico.
No quadro teórico que temos privilegiado, agir politicamente significa tomar decisões em meio a uma infinidade de possibilidades abertas pela reativação do momento articulatório (crise, deslocamento da estrutura), por meio de identificação com os processos de significação em disputa. É neste processo de identificação que as "subjetividades políticas" são criadas e formadas (HOWARTH, 2000). Como assinalado, o significante "experiência", tal como mobilizado pela pesquisa biográfica, ao permitir operar teoricamente com a ideia de sujeitos únicos e singulares, não em termos de substância ou essência, mas em sua capacidade de responder, produzir demandas de diferentes tipos e articular-se a outras, pode significar a abertura de pistas para desestabilizar sentidos cristalizados de "sujeito político".

Como dimensão do agir humano, a pesquisa (auto)biográfica no campo curricular tem oferecido, portanto, a possibilidade de transitar no entrelugar "que articula atos hegemônicos de representação e modos de subjetivação dos supostos representados em meio a estes atos" (CARVALHO; SÁ; PIMENTEL-JUNIOR, 2018, p. 33), lançando luz sobre outras significações possiveis para o significante agência que afetam o entendimento da "participação dos sujeitos na luta política pelo poder de significar o currículo" (CARVALHO; SÁ; PIMENTEL-JUNIOR, 2018, p. 29), bem como nas demais disputas pela significação de termos como: "docência", "conhecimento", "relação com o saber", "escola", "universidade", "ciência", que atravessam e configuram esse campo.

Como mencionado anteriormente, investimos na potencialidade heurística da crítica pós-fundacional, que possibilita compreender os conflitos políticos como elementos incontornáveis em qualquer configuração política/ social, apontando para o caráter sempre contingente de qualquer ordem educacional hegemônica. Essa postura epistêmica é uma aposta 
no investimento que fazemos no sentido de deslocar fronteiras que estabilizam sentidos de significantes caros ao campo curricular, na reflexão sobre os interesses contingenciais que estabilizam e desestabilizam sentidos neste campo.

Assumimos uma leitura do ato emancipatório que permite - por meio da hegemonização de cadeias definidoras de significantes, em detrimento de outras (GABRIEL, 2016) - operar de forma produtiva com a aporia entre a impossibilidade de qualquer fechamento provocado pela lembrança constante da contingência de toda e qualquer articulação hegemônica - por mais fixa e naturalizada que ela pareça - e a inevitabilidade da universalização de sentidos particulares, ainda que provisória.

Nessa perspectiva, entendemos que a compreensão do próprio texto curricular como espaço de agência (RANNIERY, 2017) se apresenta como um caminho teórico-metodológico bastante proficuo. Para tal, o diálogo com os estudos foucaultianos e os estudos feministas pós-estruturalistas têm contribuído para avançarmos em nossas reflexões sobre a produção da agência no campo curricular, a partir do entendimento de "sujeito biográfico", tal como discutido na seção anterior. Trata-se de apostar na potencialidade das histórias de vida como meio de perceber como os sujeitos do universo escolar habitam a normatividade do campo curricular de diferentes formas (RANNIERY, 2017). Para tanto, temos investido em uma compreensão de agência pensada para além do par binário resistência e sujeição e na noção de que as normas determinam a viabilidade da subjetividade humana, uma vez que ao mesmo tempo que funcionam como "regulação de poder dos corpos", elas também apresentam os modos como os sujeitos "podem habitar o mundo" (RANNIERY, 2017, p. 7).

Ao refletir sobre a temática da agência para além da concepção binária de resistência/su- jeição, a antropóloga Saba Mahmood (2005; 2006) propõe atentar para os diferentes significados de agência que emergem em meio às práticas dos sujeitos. Mahmood (2006) levanta questões analíticas que são possibilitadas quando a agência é considerada em variantes que não estão fundamentadas em termos de resistência às relações de dominação. A autora propõe a análise das práticas específicas de subjetivação por meio do exame das práticas discursivas e performativas que viabilizam a filiação dos sujeitos a uma normatividade que fornece, ela mesma, as condições necessárias para a subordinação e para a agência.

Saba Mahmood (2006) busca trabalhar com uma noção de agência que pode ser entendida por meio do que Michel Foucault (apud MAHMOOD, 2006) nomeia "paradoxo da subjetivação", compreendido como um movimento que garante a subordinação dos sujeitos às relações de poder ao mesmo tempo que produz os "meios através dos quais ele se transforma numa entidade consciente e num agente" (MAHMOOD, 2006, p. 121). Esta noção de "paradoxo da subjetivação", se produz a partir da premissa foucaultiana de que o poder, como relação de forças estratégicas, não atua somente no sentido de dominar. Mas é também produtor de formas de desejo, discursos, relações. Neste sentido, a agência é entendida como "capacidade de ação criada e propiciada por relações concretas de subordinação historicamente configuradas" (MAHMOOD, 2006, p. 123).

De modo semelhante, Butler (2014) afirma que o poder regulador não só age sobre um sujeito que existe previamente a ele, mas delimita e forma esse sujeito. Nessa concepção, o "tornar-se sujeito" é diretamente dependente da regulação (BUTLER, 2014). Neste sentido, a norma governa a inteligibilidade social da ação que não é o mesmo que a ação governada por ela. Nesta leitura, a norma é o que 
outorga inteligibilidade ao campo social. Nas palavras da autora, "a norma governa inteligibilidades, permitindo que determinadas práticas e ações sejam reconhecidas como tais, impondo uma grelha de legibilidade sobre o social e definindo os parâmetros do que será e do que não será reconhecido como domínio do social" (BUTLER, 2014, p. 253). Ou seja, os meios que garantem a subordinação dos sujeitos são os mesmos que possibilitarão que ele se torne uma agência autoconsciente. Nas palavras de Mahmood (2006):

[...] poderíamos argumentar que o conjunto de capacidades inerentes ao sujeito - ou seja, as capacidades que definem os modos da sua agência - não são o resíduo de um self não domesticado, existente antes das operações de poder, mas são, em si mesmas produto dessas operações. Este entendimento do poder e formação do sujeito permite-nos conceitualizar a agência não só como um sinônimo de resistência a relações de dominação, mas também como uma capacidade para ação criada e propiciada por relações de subordinação específicas. (MAHMOOD, 2006, p. 132)

No campo de estudos do currículo fazemos então uma aposta teórica no investimento da abordagem (auto)biográfica de discentes e docentes como experiências do tornar-se sujeito que se tecem e compõem currículos. A experiência sendo compreendida aqui como uma história que é ao mesmo tempo individual e coletiva. Neste sentido, os discursos, que constituem as trajetórias de vida dos sujeitos, não pertencem a eles isoladamente, mas têm:

[...] uma dívida com uma historicidade condensada materializada e criptografada através dos corpos As palavras não expressam os seres viventes, pois o tempo do discurso recusa a ideia de que o dito se funda no sujeito, dado que estruturas que permitem a inteligibilidade da vida pertencem a uma sociedade que tanto constitui como excede os corpos, apontando que esta temporalidade não se esgota inteiramente nos próprios corpos. (RANNIERY, 2017, p. 10)
Entendemos, portanto, que os discursos dos sujeitos não se esgotam neles, mas ecoam como marcas de uma coletividade e temporalidade que os atravessa e apostamos na potência das histórias de vida para a compreensão de como tramas curriculares criam condições de possibilidade de agência, a partir de uma abordagem que parte do indivíduo para pensar o social. Levar em conta as trajetórias dos sujeitos na escola oferece possibilidades de abrir caminhos para deixar vazar a criatividade dos modos de vida que compõem o universo curricular e não se esgotam na normatividade, mas apontam para as diferentes formas de habitar a norma. Nas palavras de Ranniery (2017):

É na não transcendência das normas que tais vidas podem fazer seu trabalho, na medida em que anunciam tanto a persistência quanto a oscilação da normatividade, o que não diminui, mas intensifica o trabalho político que podem fazer. Quando habitam a matriz normativa, indicam que as repetições das normas funcionam de modo fraturado, deslocado e heterogêneo. Por outra parte, põem em relevo que deslocar uma norma não equivale a subvertê-la, pode servir - talvez não deixe de fazê-lo - como instrumento para a sua reinscrição. (RANNIERY, 2017, p. 23)

\section{Sujeito biográfico e agência: articulações teóricas possíveis}

Cada um entre nós deve se forjar um caminho entre as vias que nos são abertas, as que nos são proibidas ou as que semeiam obstáculos sob os nossos pés. Nós não somos de uma vez só nós mesmos, nós não nos contentamos de 'ter consciência' do que nós somos; nós nos tornamos o que somos. (MAALOUF, 1998, p. 35, tradução livre) $)^{12}$

12 Chacun d'entre nous doit se frayer un chemin entre les voies où on pousse, e celles qu'on lui interdit ou qu'on sème d'embûches sous les pieds; il n'est pas d'emblée lui-même, il ne contente pas de prendre conscience de ce qu'il est; il devient ce qu'il est. (MAALOUF, 1998, p. 35) 
Essas breves reflexões sobre os significantes "sujeito" na pesquisa (auto)biográfica e "agência" na perspectiva pós-fundacional evidenciam elementos que autorizam aproximar essas duas categorias de análise permitindo, assim, potencializar a força e a coerência teórica dos argumentos que nos propomos a sustentar em nossos estudos e pesquisas do campo do currículo. Entre esses elementos, destacamos o entendimento: (i) do lugar instituinte atribuído à linguagem na produção de leituras do social; (ii) da articulação entre estrutura e sujeito e (iii) dos efeitos políticos desses entendimentos na definição e no uso da categoria analítica "sujeito".

O lugar instituinte atribuído à linguagem, percebido como elemento incontornável pelas duas abordagens - na objetivação do real, pode ser evidenciado por meio da mobilização de categorias como narrativa/relato (pesquisa biográfica) e discurso (abordagem pósfundacional). Essa percepção da linguagem se inscreve em um movimento epistêmico mais amplo que tem contribuído para fundamentar e radicalizar a crítica endereçada às leituras essencialistas do social que tendem a hegemonizar sentidos de "sociedade" e de "sujeito" que operam, como vimos, com a ideia de fundamentos últimos e transcendentais, realimentando a crença na possibilidade de pensar o social e os indivíduos como positividades transparentes. Expressões como "fato biográfico", "biografização", "articulação discursiva" e "demanda" são indicadores potentes mobilizados por essas abordagens que as distanciam de perspectivas essencialistas, abrindo pistas de investigação que, consideramos, merecem continuar a ser exploradas no campo curricular.

O segundo elemento faz referência à crítica assumida, por ambas as abordagens - e não só -, que incide tanto sobre as concepções estruturalistas e deterministas quan- to sobre as perspectivas individualistas que operam de forma dicotômica a relação entre estrutura e sujeito na compreensão política social. Ora são as forças da estrutura, percebidas como totalidades previamente definidas, que determinam as possibilidades de ação do sujeito, reduzido a um efeito da estrutura, ora são as ações do sujeito - percebido como indivíduos racionais, conscientes e autônomos - que explicariam de forma, se não exclusiva, decisiva, as transformações sociais, as possibilidades de resistência ou de subversão. Pelo exposto nas duas seções anteriores, as abordagens em foco colocam em evidência a articulação entre processos de estruturação (de uma ordem social específica, de contextos de formação como escola e universidade, de currículos hegemonizados nesses contextos) e os processos de subjetivação que produzem simultaneamente subjetividades políticas e posicionamentos de sujeito em meio a ordens sociais desigualmente estruturadas. 0 que está em jogo, nas análises inscritas nas abordagens aqui em foco, é menos o peso de cada um dos polos dessa relação e, sim, as formas assumidas pela articulação entre ambas, entendida como possibilidade da objetivação dessa relação.

Em relação ao terceiro aspecto mencionado, importa salientar a contribuição teórica dessas abordagens para pensar o "sujeito" e sua "capacidade de ação". Ao assumirem sua incompletude, pluralidade, heterogeneidade e provisoriedade, a pesquisa autobiográfica e a teoria do discurso pós-fundacional oferecem ferramentas analíticas, como procuramos destacar ao longo de nosso texto, que permitem operar na e com a contingência em meio a processos de subjetivação que se instauram em contextos produzidos e objetivados igualmente na interação com as ações dos sujeitos por meio das quais eles "se tornam presença" (BIESTA , 2013). 
Nosso propósito aqui, longe de pretender fazer uma apologia dessas abordagens, foi apresentar, ainda que de forma breve, algumas ferramentas analíticas produzidas a partir de uma postura epistêmica, comum às perspectivas em foco neste texto, nas quais vimos apostando em nossos estudos curriculares. Não se trata de afirmar "o" caminho de investigação mais potente, mas sim de contribuir para a ampliação das possibilidades teóricas na reflexão política do campo curricular, em particular no que esta incide na compreensão da produção de subjetividades.

\section{Referências}

ARFUCH, Leonor. 0 espaço biográfico. Dilemas da subjetividade contemporânea. Rio de Janeiro: EdUERJ, 2010.

BIESTA, Gertz. Para além da aprendizagem. Educação democrática para um futuro humano. Belo Horizonte: Editora Autêntica, 2013.

BUTLER, Judith. Regulações de gênero. Cadernos Pagu, Campinas, n. 42, p. 249-274, jan./jun. 2014. Disponivel em: <http://www.scielo.br/pdf/cpa/n42/01048333-cpa-42-00249.pdf>. Acesso em: 10 jan. 2019.

CARVAlHO, Maria Inez da Silva de Souza; SÁ, Maria Roseli Gomes Brito de.; PIMENTEL- JUNIOR, Clívio. Currículo, (auto)biografias e diferença: políticas e poéticas do incontrolável no cotidiano da educação em ciências. Revista e-Curriculum, São Paulo, v. 16, n. 1, p. 29-59, jan./mar. 2018. Disponivel em: <https:// revistas.pucsp.br/index.php/curriculum/article/ download/28921/25070>. Acesso em: 10 jan. 2019.

DELORY-MOMBERGER, Christine A condição biográfica. Ensaios sobre a narrativa de si na modernidade avançada. Tradução de Carlos Galvão Braga, Maria da Conceição Passeggi e Nelson Patriota. Natal: EDUFRN, 2012.

. Fundamentos epistemológicos da pesquisa biográfica em Educação. Educação em Revista, Belo Horizonte, v. 27, n. 1, p. 333-346, abr. 2011a. Disponivel em: <http://www.scielo.br/pdf/edur/v27n1/v27n1a15. pdf>. Acesso em: 10 jan. 2019.

Os desafios da pesquisa biográfica em educação. In: SOUZA, Elizeu Clementino de. (Org.). Memória (auto)biografia e diversidade. Questões de método e trabalho docente. Salvador: EDUFBA, 2011b. p. 43-57.

Experiencia y formation. Biografization, biograficidad y heterobiografia. Revista Mexicana de Investigation Educativa, v. 19, n. 62, p. 695-710, jul./sep. 2014.

. La recherche biographique ou la construction partagée du savoir singulier. Salvador: Revista Brasileira de Pesquisa (Auto)Biográfica, v. 1, n. 1, p. 133-147, jan./abr. 2016.

Disponivel em: <https://www.revistas.uneb.br/index.php/rbpab/article/download/2527/1712>. Acesso em: 10 jan. 2019.

De quel savoir la recherche biographique en education est-elle le nom? Paris: Revue Le sujet dans la Cité, Actuels, La recherche biographique Quels savoirs pour quelle puissance d'agir? n. 6, p. 11-24, mar. 2017.

FOUCAULT, Michel. Les mots et les choses. Paris: Gallimard, 1966.

GABRIEL, Carmen Teresa. Conhecimento escolar e emancipação: uma leitura pós-fundacional. Cadernos de Pesquisa [on-line], v. 46, n. 156, p. 104-130, jan./mar. 2016. Disponível em: <http://www.scielo. $\mathrm{br} / \mathrm{pdf} / \mathrm{cp} / \mathrm{v} 46 \mathrm{n} 159 / 1980-5314-\mathrm{cp}-46-159-00104$. pdf>. Acesso em: 10 jan. 2019.

GABRIEL, Carmen Teresa. Conteúdo-rastro: um lance no jogo da linguagem do campo curricular. Currículo sem Fronteiras, v. 17, n. 3, p. 515-538, set./dez. 2017.

GABRIEL, Carmen Teresa. Objetivação e subjetivação nos currículos de licenciaturas: revisitando a categoria saber docente. Revista Brasileira de Educação, RBE, v. 23, p. 1-22, 2018a. Disponivel em: <http://www.scielo.br/pdf/rbedu/v23/1809-449X-rbedu-23-e230071.pdf>. Acesso em: 10 jan. 2019.

GABRIEL, Carmen Teresa. Relação com o saber: uma 
proposta de releitura pós-fundacional, In: LOPES, A. C.; OliveIRA, A. L.; OLIVEIRA, G. G. S. de. A teoria do discurso na pesquisa em educação. Recife: Editora UFPE, 2018b. p. 217-249.

GAUJELAC, Vincent de. Qui est je? Sociologie clinique du sujet. Paris: Éditions du Seuil, 2009.

HOWARTH, David. Discourse. Buckinghtam; Philadelphia: Opens University Press, 2000.

LACLAU, Ernest; MOUFFE, Chantal. Hegemonía y estratégia socialista. Hacia una radicalización de la democracia. Buenos Aires: Fondo de Cultura Económica de Argentina, 2004.

LAROSSA, Jorge. Notas sobre a experiência e o saber de experiência. Revista Brasileira de Educação, n. 19, p. 20-29, jan./fev./mar./abr. 2002. Disponível em: <http://www.scielo.br/pdf/rbedu/n19/n19a02.pdf>. Acesso em: 10 jan. 2019.

LEITE, Miriam Soares. Adolescência e juventude no ensino fundamental: signifixações no contexto da prática curricular. Revista Teias, Rio de Janeiro, v. 11, n. 22, p. 55-74, mai./ago. 2010. Disponível em: <https://www.e-publicacoes.uerj.br/index.php/revistateias/article/viewFile/24115/17093>. Acesso em: 10 jan. 2019.

MAALOUF, Amin. Les identités meurtrières. Paris: Le Livres de Poche, 1998.

MAHMOOD, Saba. Politics of piety: the islamic revival and the feminist subject. Princeton: Princeton University Press, 2005.

- Teoria feminista, agência e sujeito libertatório: algumas reflexões sobre o revivalismo islâmico no Egito. Etnográfica, v. 10, n. 1, p. 121-158, mai. 2006. Disponível em: <http://www.scielo.mec.pt/pdf/etn/ v10n1/v10n1a07.pdf>. Acesso em: 10 jan. 2019.
MARCHART, Olivier. El pensamiento político posfun-

dacional: la diferencia política en Nancy, Lefort, Badiou y Laclau. Buenos Aires: Fondo de Cultura Económica, 2009.

NIEWIADOMSKI, C. Recherche biographique et clinique narrative. Entendre et écouter le sujet contemporain. Toulouse: Editions Erès, 2012.

RANNIERY, Thiago. Currículo, normatividade e políticas de reconhecimento a partir de trajetórias escolares de "meninos gays". Education Policy Analysis Archives, v. 25, p. 1-32, 2017. Disponivel em: <https://dialnet.unirioja.es/servlet/articulo?codigo $=6056887 \&$ orden=0\&info=link>. Acesso em: 10 jan. 2019.

RETAMOZO, Martín. Construtivismo: epistemologia y metodologia em las ciencias sociales. In: DE LA GARZA TOLEDO, E; LEYVA, G. (Orgs). Tratado de metodologia de las ciencias sociales: perspectivas actuales. México: FCE; UAM, 2012. p. 325-350.

SCOTT, Joan W. Experiência. In: SILVA, A. L. da.; LAGO, M. C. de S.; RAMOS, T. R. O. (Orgs.). Falas de gênero. Tradução de Ana Cecília Adoli Lima. Santa Catarina: Editora Mulheres, 1999. p. 21-55.

SOMMERER, E. L'école d'Essex et la théorie politique du discours: une lecture 'postmarxiste' de Foucault. Raisons politiques, n. 19, p. 193-209, 2005.

SOUZA, Elizeu Clementino de. (Auto)biografia, histórias de vida e práticas de formação. In: NASCIMENTO, A. D.; HETKOWSKI, T. M. (Orgs.) Memória e formação de professores. Salvador: EDUFBA, 2007. p. 59-74.

Recebido em: 19/02/2019

Aprovado em: 27/05/2019

Carmen Teresa Gabriel é professora Titular de Currículo da UFRJ, bolsista de produtividade do CNPq, Cientista de Nosso Estado /FAPERJ, professora da Faculdade de Educação da UFRJ e do Programa de pós-graduação dessa mesma instituição (PPGE/UFRJ), professora do Programa de Pós-Graduação - ProfHistória, coordenadora do Laboratório d Núcleo de Estudos de Currículos da UFRJ (LaNEC) e do Grupo de Estudos Currículo Conhecimento e Ensino de História (GECCEH), atualmente ocupa o cargo de direção da Faculdade de Educação da UFRJ. e-mail: carmenteresagabriel@gmail.com 
Natália Rodrigues Mendes é Doutoranda do PPGE (Programa de Pós-Graduação em Educação) da Universidade Federal do Rio de Janeiro, membro do Grupo de Estudos Currículo Conhecimento e Ensino de História (GECCEH) e professora de História da rede municipal do Rio de Janeiro. e-mail: nataliagaati@yahoo.com.br

Pça Ns Auxiliadora, Leblon, Rio de Janeiro - RJ, Brasil. CEP: 22441-050. Telefone: (21) 2274-4497 